\title{
Convective Enhancement of Icing Roughness Elements in Stagnation Region Flows
}

\author{
Michael T. Hughes ${ }^{1}$ and Stephen T. McClain ${ }^{2}$ \\ Baylor University, Waco, Texas, 76798 \\ Mario Vargas ${ }^{3}$ and Andy Broeren ${ }^{4}$ \\ NASA Glenn Research Center, Cleveland, Ohio, 44135
}

\begin{abstract}
To improve existing ice accretion simulation codes, more data regarding ice roughness and its effects on convective heat transfer are required. To build on existing research on this topic, this study used the Vertical Icing Studies Tunnel (VIST) at NASA Glenn Research to model realistic ice roughness in the stagnation region of a NACA 0012 airfoil. Using the VIST, a test plate representing the leading $2 \%$ chord of the airfoil was subjected to flows of $7.62 \mathrm{~m} / \mathrm{s}(25 \mathrm{ft} / \mathrm{s}), 12.19 \mathrm{~m} / \mathrm{s}(40 \mathrm{ft} / \mathrm{s})$, and $16.76 \mathrm{~m} / \mathrm{s}(55 \mathrm{ft} / \mathrm{s})$. The test plate was fitted with 3 surfaces, each with a different representation of ice roughness: 1) a control surface with no ice roughness, 2) a surface with ice roughness with element height scaled by 10x and streamwise rough zone width from the stagnation point scaled by 10x, and 3) a surface with ice roughness with element height scaled by $10 x$ and streamwise rough zone width from the stagnation point scaled by 25x. Temperature data from the tests were recorded using an infrared camera and thermocouples imbedded in the test plate. From the temperature data, a convective heat transfer coefficient map was created for each case. Additional testing was also performed to validate the VIST's flow quality. These tests included five-hole probe and hot-wire probe velocity traces to provide flow visualization and to study boundary layer formation on the various test surfaces. The knowledge gained during the experiments will help improve ice accretion codes by providing heat transfer coefficient validation data and by providing flow visualization data helping understand current and future experiments performed in the VIST.
\end{abstract}

\section{Nomenclature}

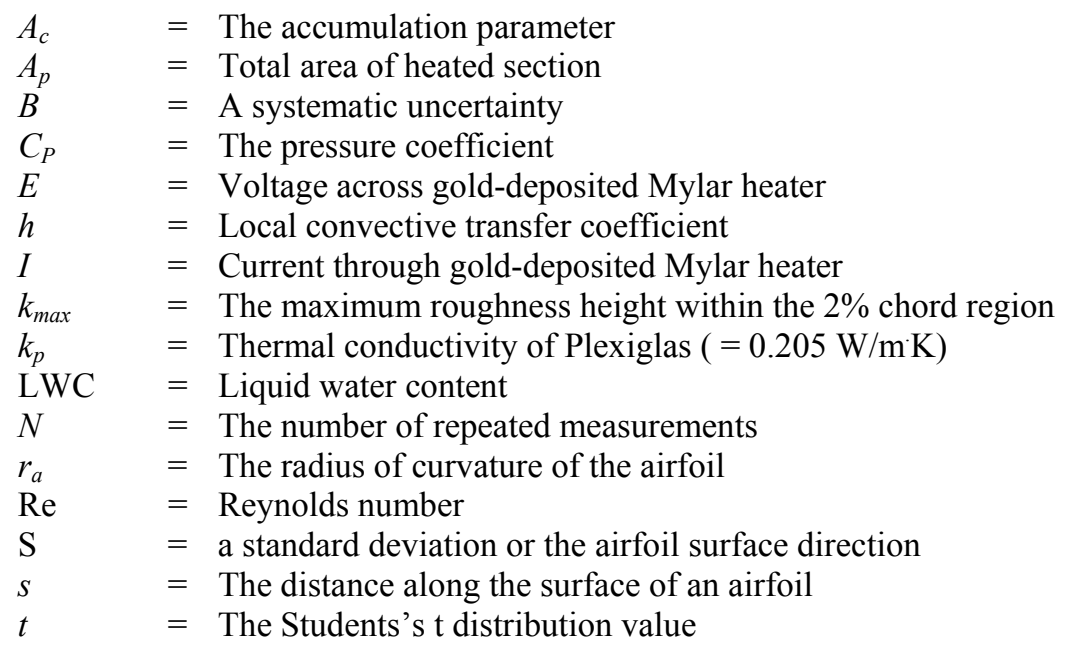

${ }^{1}$ Graduate Research Assistant, Department of Mechanical Engineering, One Bear Place \#97356, non-member.

${ }^{2}$ Associate Professor, Department of Mechanical Engineering, One Bear Place \#97356, AIAA Senior Member.

${ }^{3}$ Aerospace Engineer, Icing Branch, 21000 Brookpark Rd., AIAA Associate Fellow.

${ }^{4}$ Aerospace Engineer, Icing Branch, 21000 Brookpark Rd., AIAA Associate Fellow. 


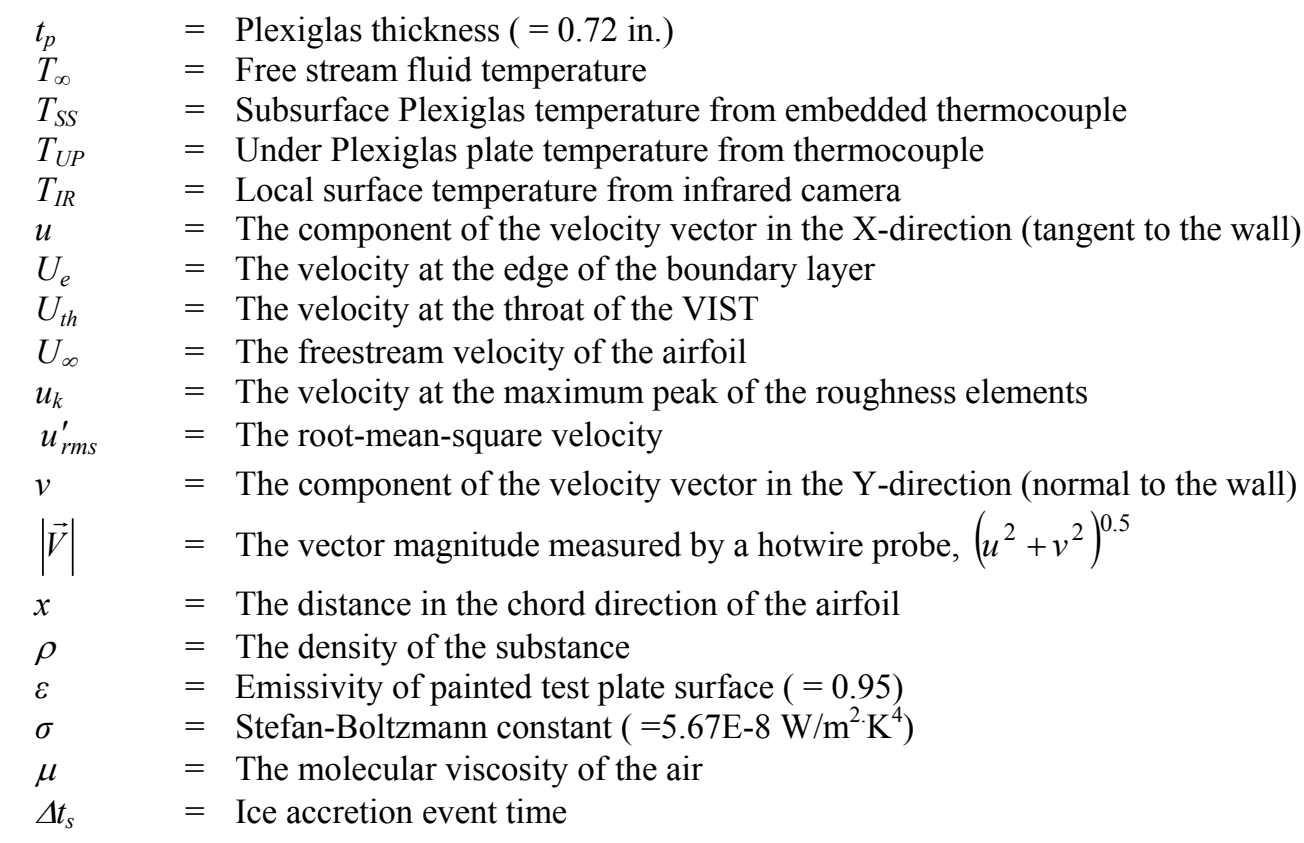

\section{Introduction}

Qince the 1940's NASA's Icing Branch at Glenn Research Center has been performing valuable research and $\checkmark$ testing to improve the safety of aircraft flying in icing conditions [1]. Their mission is accomplished through a wide variety of operations including the creation of software simulation tools which predict the accretion of ice on aircraft surfaces during flight. One of the leading ice accretion codes, LEWICE, is developed by researchers at NASA Glenn [2] and is used widely throughout the aeronautics industry.

Ice roughness is an important factor to model in ice accretion codes because it couples the fluid flow, heat transfer, and droplet impingement processes [3]; however, it is difficult to characterize due to the chaotic nature of its formation [4]. Although several mechanisms for heat transfer exist on an airfoil, the prediction of ice growth rates and ice shape formation is most highly sensitive to convective heat transfer since this is the predominant mode of heat transfer in aircraft icing [5]. Since ice roughness is so closely coupled to convective heat transfer, a change in the ice roughness characteristics (element size, element spacing, etc.) will drastically impact the convective heat transfer from a surface and, therefore, the amount and rate of ice accretion.

Ice accretion codes are currently limited in their capabilities to accurately predict ice accretion due, in part, to the use of simplified ice roughness models. In LEWICE, an estimate of ice roughness height is made based on the sandgrain equivalent model [2]. Convective heat transfer coefficients are then determined from an integral boundary layer calculation, which uses the predicted ice roughness height. The equivalent sand-grain roughness height is determined by an empirical correlation as a function of the freezing fraction at the stagnation point. The current approach used by LEWICE is conceptually unsatisfactory since sand-grain roughness is very different from realistic ice roughness in both size and distribution density [6]. The LEWICE correlation is very simplistic in its use of only one variable (stagnation point freezing fraction) to estimate the roughness height for the entire range of icing conditions.

Real ice roughness created on aircraft surfaces differs from the surfaces used for the classical correlations in many important ways. Those differences being:

1) Ice roughness occurs with random distributions of roughness elements of different size and location along the surface,

2) Ice roughness properties vary along the flow direction including exhibiting an abrupt smooth-to-rough surface transition,

3) Because of the varying ice growth rates, surfaces with ice roughness exhibit changing thermal boundary conditions along the flow direction,

4) Surfaces with ice roughness experience mildly to highly accelerating flow because of the shape of the airfoil, 
5) Atmospheric flows and flows inside the Icing Research Tunnel may experience elevated levels of freestream turbulence,

6) Ice roughness exhibits many different roughness element shapes, and

7) Because of the local freezing of the liquid water (Stefan condition), the surface of the ice roughness exhibits essentially a constant temperature acting as a surface with near infinite thermal conductivity even though ice in isolation has a relatively low thermal conductivity.

Different studies in this series have isolated different aspects of realistic ice roughness in an attempt to explain the differences between the predicted values from the traditional correlations and the convection values required to accurately predict ice shapes in LEWICE. Tecson and McClain [7] investigated the enhancement of surfaces with random distributions similar to those found on airfoils with ice roughness in flows with minimal freestream acceleration. The surfaces studied by Tecson and McClain [7] were created using a Lagrangian droplet simulation of the beading and coalescence process [8]. The resulting bead pattern was modified to match the characteristics of surfaces measured from historical roughness studies in the IRT $[6,9]$.

Walker et al. [10] expanded on the study of Tecson and McClain [8] by imposing different flux boundary conditions. Walker et al. [10] found that although the different boundary conditions produced slight variations in the measured convection coefficients, the relative enhancement above the smooth turbulent case was not significant for a given roughness pattern. In any case, the varying thermal boundary conditions did not replicate the significant differences between LEWICE predictions and experimental measurements of convection coefficients.

Shannon and McClain [11] further expanded on the investigations of Tecson and McClain [8] and Walker et al. [10] by 1) including realistic ice roughness variations as measured in the IRT using laser scanning and 2) including a flow acceleration profile along the flow direction that matches the profile exhibited by the airfoils tested in the IRT. The measurements of Shannon and McClain [11] focused on replicating the flow acceleration exhibited on leading $17.1 \%$-chord region of a NACA 0012 . However, because they chose to perform the tests by heating a flat plate and employ a ceiling insert to provide flow acceleration, the stagnation region or $2 \%$-chord of the leading edge of the NACA 0012 was not replicated or heated as would be found on a real airfoil. Fortunately, the ice accretion cases replicated by Shannon and McClain [11] were short icing events with accretion times on the order of 1.5 minutes, and substantial ice roughness is not exhibited in the 2\%-chord region of the airfoil [11].

As noted by Shin [6], at short icing event times, three distinct regions of ice roughness will appear: 1) a smooth zone near the stagnation, 2) a region of roughness downstream of the stagnation region, and 3) a region of feather roughness which decays in height as the distance from stagnation point increases. The purpose of this study was to investigate the enhancement caused by ice roughness in the leading 2\%-chord region of a NACA 0012 airfoil that had been exposed to a supercooled cloud long enough so that the roughness propagates into the $2 \%$-chord region of the airfoil but just before the stagnation region of the airfoil completely closes. That is, the study investigated the convective enhancement of the roughness in the stagnation region just before the smooth zone is closed by the ice shape development. Roughness in the $2 \%$-chord region is critical because it drastically increases the convective surface area and depending on the size of the roughness may cause the flow to become turbulent drastically increasing convective heat transfer rates in the stagnation region.

To achieve the objective of the study, a heated test plate was installed in the Vertical Icing Studies Tunnel (VIST) at the NASA Glenn Research Center. The VIST is a stagnation flow wind tunnel designed for the simulation and examination of ice accretion physics in the stagnation region of large aircraft wings [12]. Roughness panels were created for the heated test plate that exhibited roughness characteristics and variations matching those of a 53.3-cm (21-in.) NACA 0012 which had been exposed to a supercooled icing event. The plates were then heated while exposed to three flow situations. The surface temperatures were measured using an infrared camera and then used to determine the local convection coefficients along the rough surfaces. The resulting measurements will serve as an important convective heat transfer benchmark for ice accretion codes and will serve as an important reference for future investigations of stagnation region roughness enhancement performed in the VIST.

\section{Methodology}

All testing was performed at NASA Glenn Research Center using the Vertical Icing Studies Tunnel. The next sections detail the experimental apparatus, the methods used to create the test plates, the approach used to create the roughness panels, the testing sequence, and the approach employed to reduce the experimental measurements. 


\section{A. Testing Apparatus}

The VIST is a relatively new wind tunnel and the first research project was outlined in 2005 by White and Oliver [3] who explored the accretion of ice due to supercooled liquid water droplets. The VIST was designed specifically for the simulation and examination of ice accretion on large aircraft, and its design allows examination of the stagnation region and leading edge of an airfoil. However, unlike conventional wind tunnels, the VIST uses a flat test plate in the test section and accelerates the flow over the plate using side walls which model the flow of the desired airfoil as shown in Figure 1. Thermocouples and pressure taps are located throughout the tunnel to provide real time flow data which is accessed through the LabVIEW program used in tunnel operation.

The VIST is a closed loop tunnel with a 7.2:1 contraction ratio, a 4 in. wide throat, and a 3 HP DC motor with a max of $1750 \mathrm{rpm}$. A centrifugal fan enables throat velocities, measured using a pitot-static probe at the minimum entrance area (at the very top of Figure 1) ranging from $2 \mathrm{~m} / \mathrm{s}(6.5 \mathrm{ft} / \mathrm{s})$ to $25 \mathrm{~m} / \mathrm{s}(82 \mathrm{ft} / \mathrm{s})$.

For this study, new sidewalls were designed and constructed to allow infrared camera access to the heated test plate. Port holes were designed into the sidewalls and special mounts were constructed to hold the infrared windows. To obtain infrared images of the test plate surfaces, a FLIR SC4000 ThermoVision IR camera with a 25 $\mathrm{mm}$ lens was attached to a Velmex positioning system located above the tunnel. The two-axis positioning system allowed the camera to move laterally and rotate to view the test plate. The windows and positioning system allowed the camera to view the test plate at 7 positions allowing near full-coverage of the heated section of the test plate. Figure 2 shows the sidewalls, the portholes and mounts, the infrared windows, the infrared camera, and the two-axis positioning system used to view the test plate.

\section{B. The Heated Test Plate}

The test plate was constructed using the same thin-film gold Mylar heating approach of Tecson and McClain [7]. The test plate consisted of a Plexiglas base plate and employed a sheet of gold-deposited Mylar film as an area heater. The Plexiglas base of the plate measured $60 \mathrm{in}$. x $30 \mathrm{in}$. and had a thickness of $0.72 \mathrm{in.} \mathrm{In} \mathrm{the} \mathrm{center} \mathrm{of} \mathrm{the}$ test plate between the Plexiglas base and the surface, a gold-deposited Mylar film, which measured 7 in. x 20.5625 in., was used to provide a constant heat flux to the test plate during testing. Figure 3 presents the plate construction layers and demonstrates the heat flow occurring during testing.

Panels were attached to the base plate to effectively simulate ice roughness conditions in the VIST. The panels representing different icing surface conditions were manufactured using an Objet $303 \mathrm{D}$ printer. To gain real time temperature data from the test plate for heat loss calculations, several thermocouples were placed throughout the plate just beneath the surface and under the Plexiglas base and used to measure conduction losses through the plate to be used during the analysis. The various thermocouple locations can be seen in Figure 4.

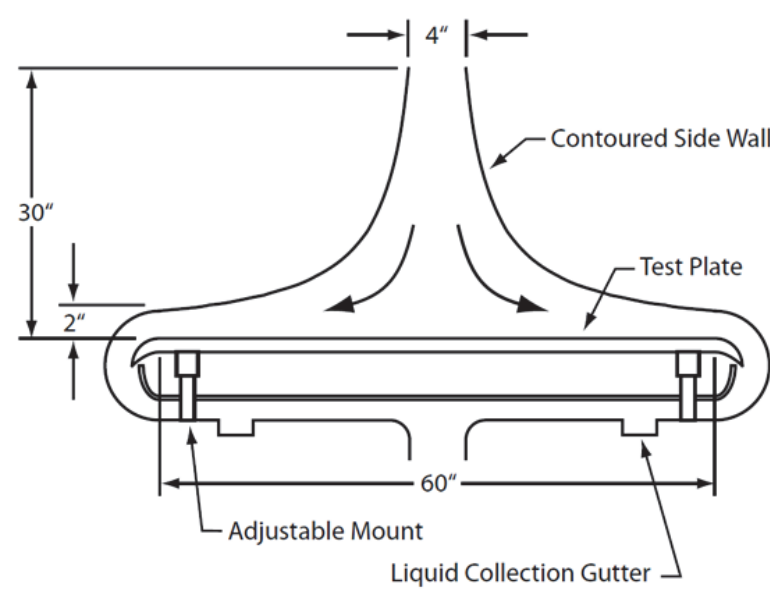

Figure 1. VIST Schematic Showing Side Wall and Test Plate Position [Reprinted from White and Oliver [3] with permission]

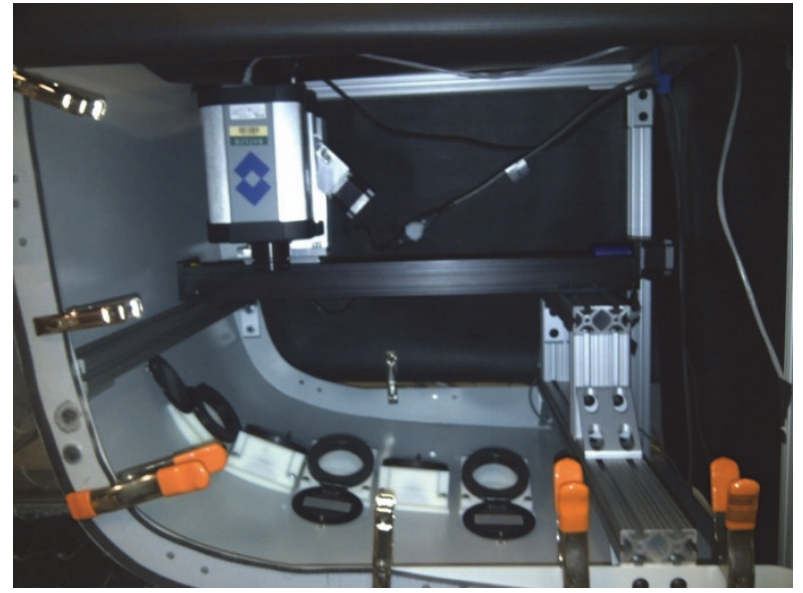

Figure 2. VIST Side Wall Showing Camera Mount Location and IR Viewports 


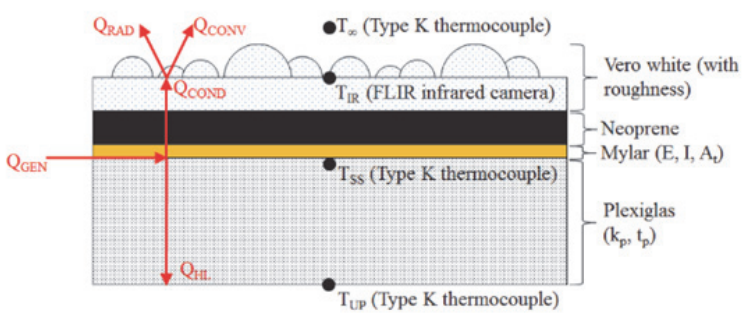

Figure 3. Cross-section of test plate displaying different layers and thermocouple positions. [Reprinted from Walker, McClain, and Shannon [1] with permission]

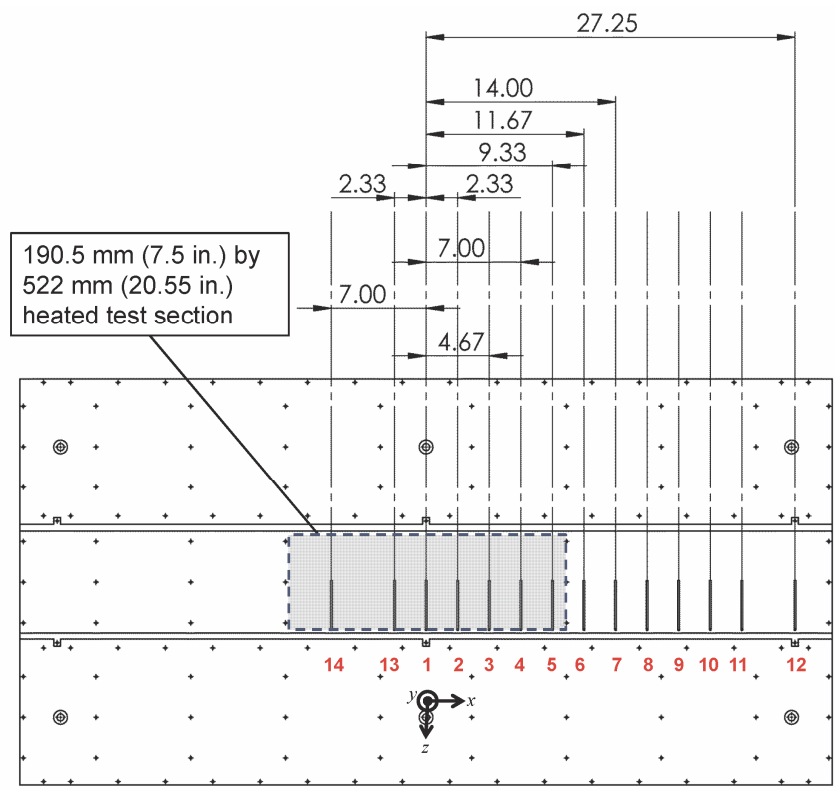

Figure 4. Streamwise Thermocouple Locations on Test Plate (Dimensions shown in inches. Thermocouple 1 is at the Stagnation Point.)

\section{Roughness Configurations}

The three test surfaces were designed to represent icing conditions on a 53.3-cm (21-in.) NACA 0012 airfoil. The first surface, acting as the control, was a smooth plate, devoid of roughness elements. This simulated an airfoil without any ice accretion.

For second and third surfaces, the desire was to match the local Reynolds number variation as demonstrated in Eq. (1) as well as maintaining the roughness Reynolds number as defined in Eq. (2).

$$
\begin{gathered}
\operatorname{Re}_{x}=\left.\frac{\rho U_{e} x}{\mu}\right|_{\text {Plate }}=\left.\frac{\rho U_{e} s}{\mu}\right|_{\substack{N A C A \\
0012}} \\
\operatorname{Re}_{k}=\left.\frac{\rho u_{k} k}{\mu}\right|_{\text {Plate }}=\left.\frac{\rho u_{k} k}{\mu}\right|_{\substack{N A C A \\
0012}}
\end{gathered}
$$

Eq. (1) indicates that as the flow moves down the test section in the X-direction from the stagnation point of the test plate, the geometry and velocity should be scaled to match the local Reynolds number of the NACA 0012 as calculated based on the distance from the stagnation point along the surface direction (S) of the airfoil. Eq. (2) indicates that as the boundary layer develops, the velocity at the maximum peaks of the roughness elements should also scale between the model and the test airfoil. Given that the boundary layers should develop similarly based on matching $\mathrm{Re}_{x}$ values, if the same geometric scaling is applied to the $\mathrm{x}$-distance from the stagnation point and to the roughness heights, then both Reynolds number scaling requirements should be matched.

The ice roughness case that the two rough surfaces were intended to match was a 53.3-cm (21-in.) NACA 0012 airfoil exposed to a $66.7 \mathrm{~m} / \mathrm{s}$ flow containing a supercooled cloud with $\mathrm{MVD}=29.7 \mu \mathrm{m}, \mathrm{LWC}=0.6 \mathrm{gm} / \mathrm{m}^{3}$, a freezing fraction of 0.217 , and an accretion time of 200 seconds resulting in an accumulation parameter $\left(A_{c}\right)$ of 0.521 where

$$
A_{c}=\frac{L W C \cdot V \cdot \Delta t_{s}}{2 \cdot r_{a} \cdot \rho_{i c e}}
$$


The case matched is the 032714.06 case studied by McClain et al. [13]. Following the test, the ice shape was scanned using the ROMER Absolute Arm laser scanning system used by the Icing Research Branch at the NASA Glenn Research Center [14]. The resulting point cloud is shown in Figure 5. The method of McClain and Kreeger [15] was then used to evaluate the roughness variations along the surface of the iced airfoil along the flow direction. Figure 6 presents the variation in the roughness maximum height (RMH), defined as 3.09 times the root-meansquare height $(\mathrm{Rq})$, along the surface of the airfoil. Figure 6 demonstrates that the roughness varies significantly in along the surface of the 032714.06 case, and in the $2 \%$-chord region the maximum RMH is around 1-mm.

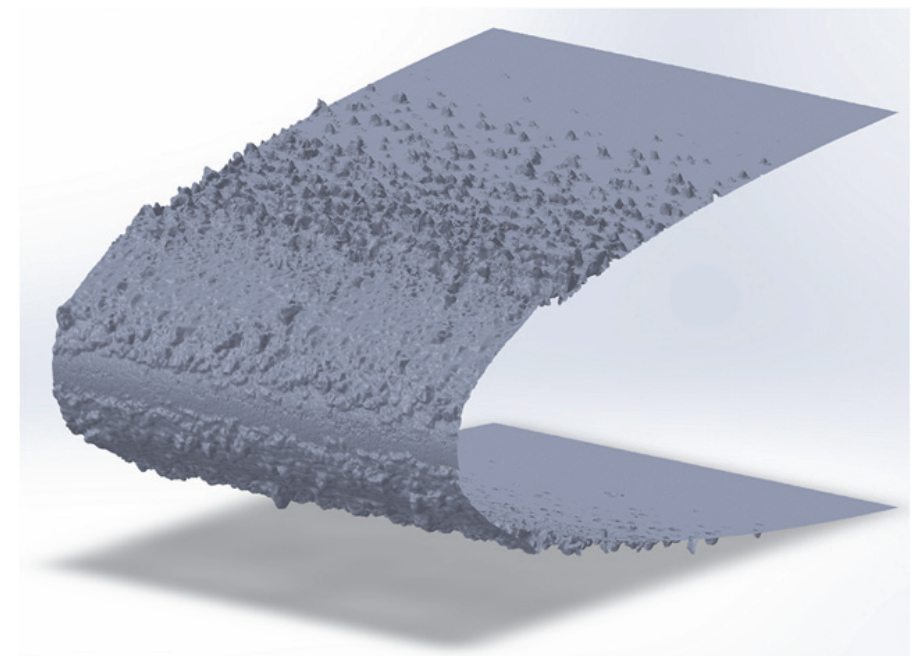

Figure 5. Laser Scan of Ice Roughness on a 21 in. NACA 0012 for the 032714.06 Case of McClain et al. [15]

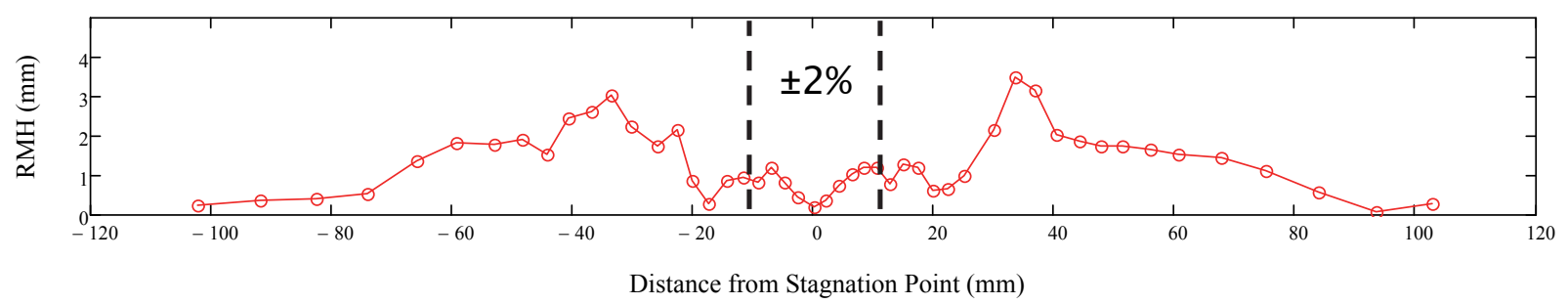

Figure 6. Variation in 99.9\% Roughness Maximum Height along the Surface of the 032714.06 Ice Shape

To match the roughness variation in the $2 \%$-chord region of the 032714.06 case, the hemispherical element distribution of Tecson and McClain [8] was used as the reference distribution. In Tecson and McClain [8], a Lagrangian simulator which simulated random droplet placement and bead coalescence was developed to generate a distribution of randomly-located hemispheres with the x10 scaled statistical description as the 052996.04 surface described by Anderson et al. [9]. The resulting distribution presented by Tecson and McClain [8] exhibited a mean element diameter of $1.037 \mathrm{~mm}$ with a standard deviation of $0.381 \mathrm{~mm}$. For the simulated 052996.04 distribution, the maximum hemisphere diameter was determined to be $1.9-\mathrm{mm}$ resulting in a maximum roughness element height of $0.95-\mathrm{mm}$. Inspecting Figure 6, the maximum height of $0.95-\mathrm{mm}$ is essentially the same size as the maximum $\mathrm{RMH}$ value found in the $2 \%$-chord region of the 032714.06 ice shape. Thus, a diameter scaling function was employed to match the roughness variations along the 032714.06 ice shape based on the simulated 052996.04 roughness distribution by Tecson and McClain [8]. The diameter scaling function is a function of the X-distance from the stagnation point and is multiplied by the local element diameters to create a new distribution with properties varying in the $\mathrm{X}$-direction.

To generate the scaling function, a series of transition functions, represented in Eq. (4), based on the hyperbolic tangent function was implemented to replicate the RMH variation along the surface of the 032714.06 case.

$$
F_{t}(x)=0.5+0.5 \tanh \left(\frac{x-x_{t}}{l_{t}}\right)
$$


The transition function expressed in Eq. (4) is zero for $x$ values much less than $x_{t}$ and is one for $x$ values much greater than $x_{t}$. The parameter $l_{t}$ governs the width of the transition zone as the function progresses from zero to one. The transitions can be multiplied by constants or functions to seamlessly transition between constant values and functions. A linear combination of three transition functions was implemented to create a scaling function to capture the variation in the RMH values of the 032714.06 surface in and near the $2 \%$-chord region of the airfoil. The resulting scaling function is shown in Figure 7.

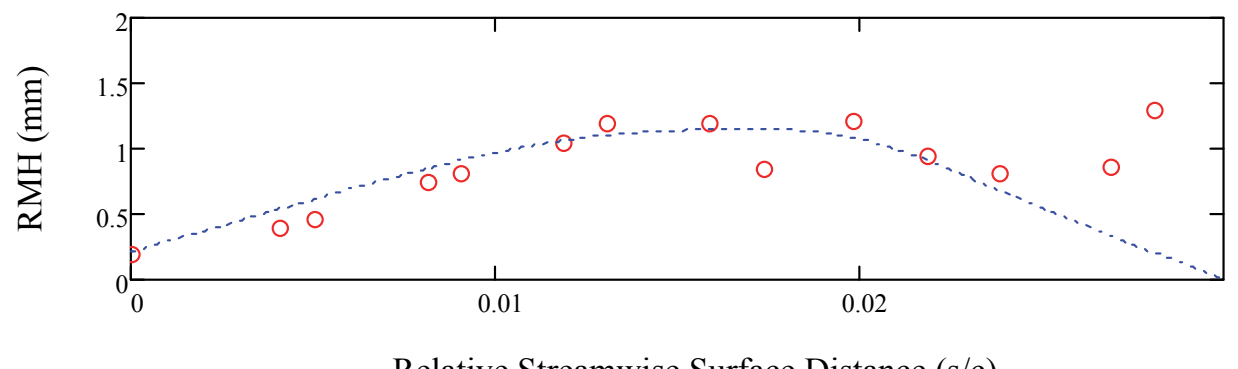

Figure 7. Roughness Variation in the Stagnation Region for the 032714.06 Case and the Roughness Scaling Function Created

While the surface variations were captured by the diameter scaling function, the system geometry must also be scaled for implementation in the VIST. In the leading $2 \%$-chord region of a NACA series airfoil, as shown in Figure 8. the pressure coefficient variation may be approximated as decreasing linearly with increasing surface distance to a value of 0.08 . The VIST was designed to replicate this acceleration along the 30 -inches (one side) of the test plate. However, the VIST was designed to replicate the leading $2 \%$-chord of the mid-span of a commercial airliner [12]. Consequently, when matching the flow over a 53.3-cm (21-in.) NACA 0012 airfoil, the wind tunnel must be run at a very low speed to use the entire test section. Observing Eq. (1), scaling the 2\%-chord of the 21 -in. NACA 0012 airfoil (0.42 in.) to the full 30 in. (single-sided) of the test section would result in having to reduce the local velocities by a factor of 72 if the density and viscosity are held constant. In replicating a $67 \mathrm{~m} / \mathrm{s}$ flow over the 21-in. NACA 0012, the throat velocity of the VIST would need to be $0.93 \mathrm{~m} / \mathrm{s}(3 \mathrm{ft} / \mathrm{s})$. This throat velocity is outside of the steady operational region of the centrifugal fan used on the VIST. Thus, employing the full test section to replicate the NACA 0012 is not practical. Further scaling a 1-mm tall roughness element similar to what would be found in ice shapes with smooth-zone closure by this geometric ratio would result in elements that were 72 $\mathrm{mm}$ (2.84 in.) tall and $144 \mathrm{~mm}$ (5.67 in) in diameter if modeled using hemispheres. Consequently, only the center $522 \mathrm{~mm}$ (20.55 in.) section of the test plate, or $\pm 261 \mathrm{~mm}( \pm 10.27 \mathrm{in}$.) from the stagnation point, was heated for this study as demonstrated in Figure 4.
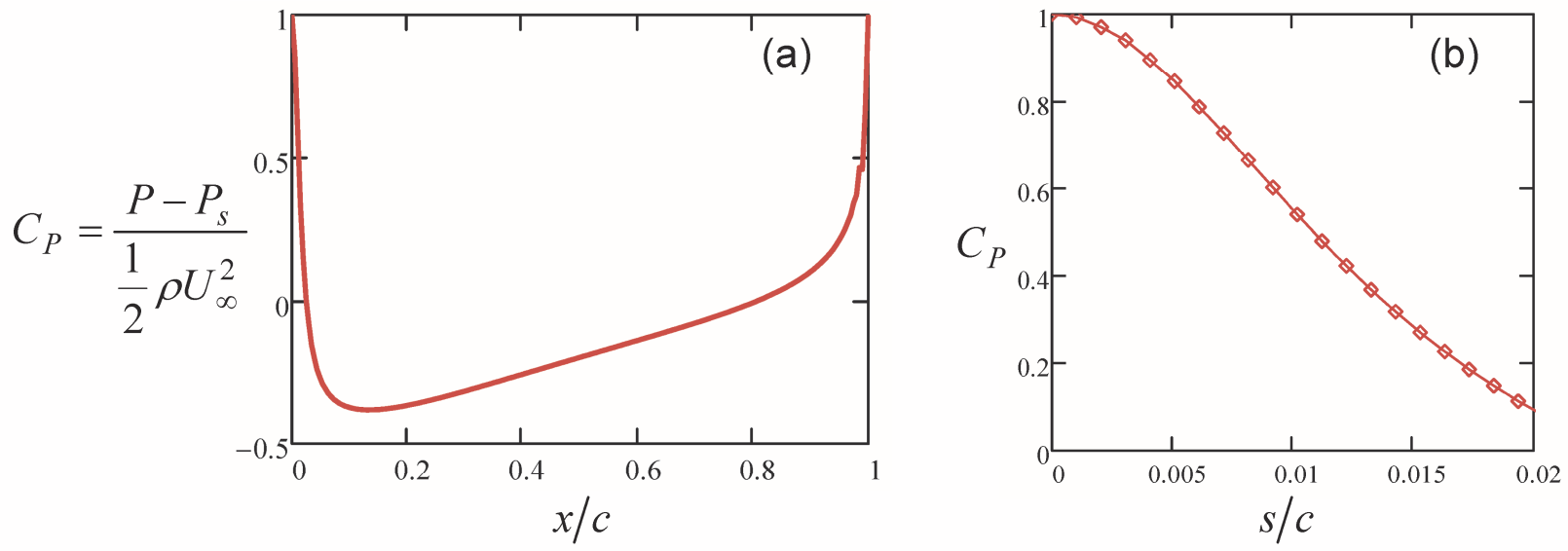

Figure 8. Inviscid Pressure Coefficient Variation along the Surface of a Low-Speed NACA 0012 Airfoil: (a) Entire Airfoil, (b) Leading 2\% Surface Distance of Chord 
Reducing geometric scaling by heating just the center section creates issues matching both $\operatorname{Re}_{x}$ and $\mathrm{Re}_{k}$. Scaling the $2 \%$-chord of the 21 -in. NACA 0012 airfoil $( \pm 0.42$ in.) to the \pm 10.27 in. center heated section results in a geometric scaling of 25 . When applied to the roughness elements, this scaling would require roughness elements 25 $\mathrm{mm}(1 \mathrm{in}$.) tall and $50 \mathrm{~mm}(2 \mathrm{in}$.) in diameter for a surface with 1-mm maximum roughness heights. Since the infrared camera used to measure surface temperatures has a $25-\mathrm{mm}$ lens, is placed approximately $380 \mathrm{~mm}(15 \mathrm{in}$.) from the surface, and must view the surface through $(75-\mathrm{mm}) 3$-in. infrared viewing windows, roughness elements of this size would cover most of the infrared viewing area of one image. This scaling would result in localized convection measurements on the roughness elements in the image and would not represent a spatially averaged measurement of heat transfer.

Reducing the scaling creates a different problem. If the roughness heights and locations are both scaled by a factor of $10 \mathrm{x}$, the width of the scaled $2 \%$ region becomes $107 \mathrm{~mm}$ (4.2 in.). To match the $2 \%$-chord Reynolds number, the throat velocity would need to be $21 \mathrm{~m} / \mathrm{s}(67 \mathrm{ft} / \mathrm{s})$, near the maximum velocity of the VIST. Operating at speeds this high increases the heat transfer rates from the plates and reduces the temperature difference between the surface that can be measured.

Consequently, a compromise was made regarding the diameter and distance scaling of the surface and roughness geometries. For the second surface, the element features and roughness extents were scaled by a factor of 10x. The second surface is referred to as the "x10x10" case. The "x10x10" surface maintains geometric scaling and allows sufficient roughness elements in the infrared images for obtaining spatial averaged values, but the scaling cannot match the Reynolds numbers original NACA 0012 iced airfoil case without operating in a very high velocity which limits the temperature resolution of the convection measurement approach. For the third surface, the element features were scaled by a factor of $10 x$, while the roughness region extents were scaled by a factor of $25 x$. The second surface is referred to as the "x10x25" case. The "x10x25" case can match the $\mathrm{Re}_{x}$ values of the NACA 0012 test case at the end of the $2 \%$-chord region, but because the roughness elements are not scaled by $25 \mathrm{x}$, the $\mathrm{Re}_{k}$ values at the $2 \%$-chord location are not matched. A depiction of the two surfaces based on floor blockage area is presented in Figure 9. The boxed areas in Figure 9 represent the heated section of the test plate depicted in Figure 4.

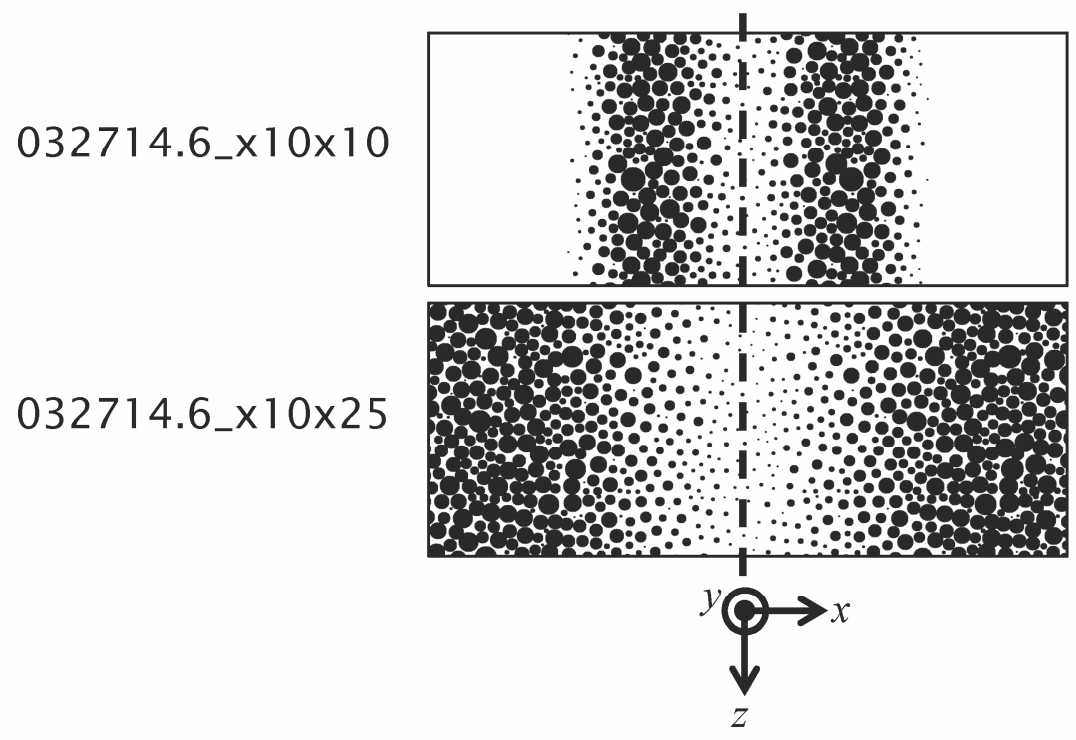

Figure 9. Depiction of the $x 10 \times 10$ and x10x25 Surfaces based on Floor Blockage Area [The X-limits of the two surface depictions is $\pm 261 \mathrm{~mm}( \pm 10.27$ in.).]

Because a compromise was made on matching both $\mathrm{Re}_{k}$ and $\mathrm{Re}_{x}$, the convection from the surfaces was quantified using three different velocities: $7.62 \mathrm{~m} / \mathrm{s}(25 \mathrm{ft} / \mathrm{s}), 12.19 \mathrm{~m} / \mathrm{s}(40 \mathrm{ft} / \mathrm{s})$, and $16.76 \mathrm{~m} / \mathrm{s}(55 \mathrm{ft} / \mathrm{s})$. Table 1 presents a summary of the test cases and the $\mathrm{Re}_{k}$ and $\mathrm{Re}_{x}$ achieved compared to the iced NACA 0012 airfoil case that was the initial objective for modelling. Since the roughness elements used in this effort are much taller than the unperturbed boundary layer heights for either of the cases, which are expected to be less than 3-mm for all of the cases used based on Twaites-based predictions for laminar flow, $u_{k}$ was assumed to be equal the $U_{e}$ in Eq. (2) for the results of Table 1. 
Table 1. Summary of Test Case Design Parameters Compared to the Modelling Objective

\begin{tabular}{|c|c|c|c|c|c|c|c|c|}
\hline Surface & $\begin{array}{c}U_{\text {th }} \text { or } U_{\infty} \\
(\mathrm{m} / \mathrm{s})\end{array}$ & $\begin{array}{c}x_{2 \%} \text { or } s_{2 \%} \\
(\mathrm{~mm})\end{array}$ & $U_{e, 2 \%}$ & $k_{\max , 2 \%}$ & $\begin{array}{c}\rho \\
\left(\mathrm{kg} / \mathrm{m}^{3}\right)\end{array}$ & $\begin{array}{c}\mu \times 10^{6} \\
\left(\mathrm{Ns} / \mathrm{m}^{2}\right)\end{array}$ & $\mathrm{Re}_{x 2 \%}$ & $\mathrm{Re}_{k 2 \%}$ \\
\hline $\mathrm{x} 10 \times 10$ & 7.62 & 107 & 2.74 & 10.6 & 1.219 & 18.4 & 19,415 & 1,923 \\
\hline $\mathrm{x} 10 \times 25$ & 7.62 & 261 & 4.28 & 10.6 & 1.219 & 18.4 & 73,964 & 3,004 \\
\hline $\mathrm{x} 10 \times 10$ & 12.19 & 107 & 4.38 & 10.6 & 1.219 & 18.4 & 31,059 & 3,077 \\
\hline $\mathrm{x} 10 \times 25$ & 12.19 & 261 & 6.84 & 10.6 & 1.219 & 18.4 & 118,322 & 4,805 \\
\hline $\mathrm{x} 10 \times 10$ & 16.76 & 107 & 6.02 & 10.6 & 1.219 & 18.4 & 42,702 & 4,230 \\
\hline $\mathrm{x} 10 \times 25$ & 16.76 & 261 & 9.41 & 10.6 & 1.219 & 18.4 & 162,681 & 6,607 \\
\hline NACA 0012 & 66.7 & 10.7 & 63.8 & 1.15 & 1.306 & 17.2 & 51,978 & 5,586 \\
\hline
\end{tabular}

\section{Test Procedure}

During each day of testing, calibrations were performed to reduce uncertainty and improve the quality of the data collected. The tunnel was left cold overnight to ensure an equilibrium temperature throughout the testing apparatus. The morning of testing, a LabVIEW software program that was used to run and monitor the VIST was activated and used to record baseline temperature and pressure data. Then, infrared images were recorded at each of the 7 positions for 10 seconds at 10 frames per second. The unheated infrared images provided a baseline surface temperature map, to which the test runs performed following the calibration could be compared. Taking the difference between the test data and the calibration data minimized total uncertainty by substantially reducing the systematic uncertainty of the FLIR camera and the thermocouples placed throughout the test section.

Following calibration, the LabVIEW program was used to select the desired upstream flow velocity and start the tunnel. For each test, the VIST's cooling system was activated and set to $65^{\circ} \mathrm{F}$. The thin-film heater power supply was then activated and set to the desired input current and voltage. Two multimeters were used to verify the voltage leaving the power supply and the voltage across the thin-film heater throughout the duration of the test. Temperatures throughout the test section were then monitored using the LabVIEW software to determine when the tunnel had achieved stable temperatures. The process of reaching steady state typically required two hours. Once the tunnel had achieved stable temperatures, denoting steady state, the infrared camera was used to record images for 10 seconds at 10 frames per second at each of the 7 positions. These recorded images provided a detailed temperature distribution of the test plate surface. The LabVIEW program used to operate the tunnel also recorded thermocouple data throughout the duration of the test which was used to determine the conduction and radiation losses.

\section{E. Convection Coefficient Calculations}

Following acquisition of the raw data, the convective heat transfer coefficient at each point was calculated using Eq. (5).

$$
h_{i, j}=\frac{\frac{E I}{A_{p}}-\frac{k_{P}\left(T_{S S}-T_{U P}\right)}{t_{P}}-\sigma \varepsilon\left(T_{I R_{i, j}}^{4}-T_{w}^{4}\right)}{\left(T_{I R_{i, j}}-T_{\infty}\right)}
$$

Eq. (5) can be divided into several parts. The first term in the numerator represents the heat flux being supplied to the test plate. The second term represents the heat loss per unit area due to conduction through the Plexiglas base, with $T_{S S}$ and $T_{U P}$ being the plate thermocouple temperatures acquired from the tunnel recording software during each data set. The third term represents the heat loss per unit area due to radiation, where $T_{I R_{i, j}}$ is the infrared camera measurement at each i,j pixel, and $T_{\infty}$ is the freestream temperature.

To extract the needed variables listed above, the raw data was processed using several MATLAB scripts. The infrared images taken from both the calibration and the tests were averaged over the 10 seconds that they were recorded. Then, the difference between the tests and the calibration data was taken. The most significant processing was mapping the individual images to a single, continuous, pixel map. Because the images were taken through the infrared windows at various streamwise locations and camera angles, the correlation of pixels per inch was not constant between the images. In order to rectify this and scale the images to match each other, reference images were taken with the thermocouple locations marked on the test surface. Because the distances between the thermocouples were known, the ratio of pixels per inch for each image could be measured. Once this was calculated, the images were scaled to a common reference and mapped to a continuous pixel map. To keep the resolution of the 
continuous pixel map, linear interpolation of the individual pixels was performed to achieve a ratio of 100 pixels per inch. The finalized continuous pixel map was then used to calculate the convective heat transfer coefficient from Eq. (5).

\section{F. Uncertainty Analysis}

Uncertainty calculations for the convective heat transfer values were determined using the large sample size approach of Coleman and Steele [16], which is an extension of the approach of Kline and McClintock [17]. The uncertainties for each experimentally measured quantity used in Eq. (5) are presented in Table 2.

The main benefit of the in situ calibration performed before testing each day was the reduction of the instrument error of the infrared temperature measurements. By taking the difference in between the calibration and test temperature values, the systematic uncertainties in the temperature measurements were all correlated. Thus, systematic uncertainty propagating into the resulting convection coefficients contributed by the temperature measurements was negligible.

Table 2. Uncertainty Values for Convective Heat Transfer Coefficient Measurements

\begin{tabular}{|c|c|c|}
\hline Variable & Systematic Uncertainty & Total Uncertainty \\
\hline E & $B_{E}=0.03 \% E$ & $\sqrt{B_{E}^{2}+\left(\frac{t S_{E}}{\sqrt{N_{E}}}\right)^{2}}$ \\
\hline$I$ & $B_{I}=1.0 \% I$ & $\sqrt{B_{I}^{2}+\left(\frac{t S_{I}}{\sqrt{N_{I}}}\right)^{2}}$ \\
\hline$A_{t}$ & $B_{d}=1 / 32^{\prime \prime}$ & $\sqrt{\left(B_{d} W_{h a}\right)^{2}+\left(B_{d} L_{h a}\right)^{2}}$ \\
\hline$t_{p}$ & $B_{d}=1 / 32^{\prime \prime}$ & $B_{d}$ \\
\hline$T_{I R}$ & $B_{T}=2 \mathrm{~K}$ & $\sqrt{B_{T}^{2}+\left(\frac{t S_{T_{I R}}}{\sqrt{N_{T_{I R}}}}\right)_{r u n}^{2}+\left(\frac{t S_{T_{I R}}}{\sqrt{N_{T_{I R}}}}\right)_{c a l}^{2}}$ \\
\hline$T_{S S}$ & $B_{T}=2 \mathrm{~K}$ & $\sqrt{B_{T}^{2}+\left(\frac{t S_{T_{S S}}}{\sqrt{N_{T_{S S}}}}\right)_{\text {run }}^{2}+\left(\frac{t S_{T_{S S}}}{\sqrt{N_{T_{S S}}}}\right)_{c a l}^{2}+\left(\frac{t S_{T_{I R}}}{\sqrt{N_{T_{I R}}}}\right)_{c a l}^{2}}$ \\
\hline$T_{U P}$ & $B_{T}=2 \mathrm{~K}$ & 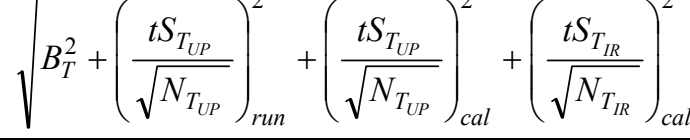 \\
\hline$T_{\infty}$ & $B_{T}=2 \mathrm{~K}$ & 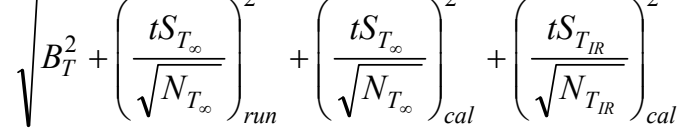 \\
\hline
\end{tabular}

\section{Results and Discussion}

The following sections discuss the convective heat transfer coefficient data obtained and further validation testing performed in the VIST. This additional testing was performed to validate the VIST flow qualities, and to quantify the flow qualities expected prior to testing.

\section{A. Convective Heat Transfer Coefficient Data}

Figures 10-12 present the convective heat transfer coefficient results calculated from the experimental data. Figures 10-12 show the data for the $7.62 \mathrm{~m} / \mathrm{s}(25 \mathrm{ft} / \mathrm{s}), 12.19 \mathrm{~m} / \mathrm{s}(40 \mathrm{ft} / \mathrm{s})$, and $16.76 \mathrm{~m} / \mathrm{s}(55 \mathrm{ft} / \mathrm{s})$ cases, respectively. Each figure contains results for each of the 3 sections: the smooth plate, the 10x10x surface, and the $10 \mathrm{x} 25 \mathrm{x}$ surface. Artifacts from the infrared viewing windows were mostly removed from the final figures by the 
mapping approach employed. However, because of the lack of overlap in the infrared images near the 121-mm (4.75 in) mark, some of the artifacts remained in the convection coefficient maps.

In Figures 10-12, the values of the convection coefficient are typically in the $30 \mathrm{~W} /\left(\mathrm{m}^{2} \cdot \mathrm{K}\right)$ on the floors of the roughness panels. The typical uncertainty of convection coefficients on the floor region is $2 \mathrm{~W} /\left(\mathrm{m}^{2} \cdot \mathrm{K}\right)$. For the rough surfaces in Figures 9-11, the individual roughness elements stand out in the maps. As one observes the convection coefficients moving up the roughness elements (especially on the forward facing side of the roughness elements) the convection coefficients increase drastically. As the elements protrude through the boundary layer, the elements interact with much colder and much faster fluid. As a consequence, the surface temperature of the largest roughness elements is very close to the temperature of the freestream fluid. Figure 11 shows that at the highest velocity investigated, $16.76 \mathrm{~m} / \mathrm{s}(55 \mathrm{ft} / \mathrm{s})$, the local apparent convection coefficients approach $250 \mathrm{~W} /\left(\mathrm{m}^{2} \cdot \mathrm{K}\right)$. Because the roughness element surface temperatures are so close to the freestream temperatures $\left(T_{I R}-T_{\infty} \approx 1 \mathrm{~K}\right)$, the uncertainties in the areas with the highest convection coefficients approach $75 \mathrm{~W} /\left(\mathrm{m}^{2} \cdot \mathrm{K}\right)$.

Comparing Figures 10-12 for a given surface, the higher velocities produce significantly higher convection coefficients. In Figure 10 shows that the maximum local heat transfer coefficients approach $200 \mathrm{~W} /\left(\mathrm{m}^{2} \cdot \mathrm{K}\right)$ for the $7.62(25 \mathrm{ft} / \mathrm{s})$ case, while Figure 12 shows that the maximum local convection coefficients are above $250 \mathrm{~W} /\left(\mathrm{m}^{2} \cdot \mathrm{K}\right)$ for the $16.76 \mathrm{~m} / \mathrm{s}(55 \mathrm{ft} / \mathrm{s})$ case.

\section{B. VIST Flow Validation}

In addition to the convective heat transfer coefficient experiments performed, several flow validation tests were performed, the first test being vertical and horizontal 5-hole probe traces. The horizontal trace was done approximately $10 \mathrm{in}$. above the surface of the test plate. Because access to the test section was limited to areas directly under the infrared access windows, the vertical traces were taken at $7 \mathrm{in.,} 8 \mathrm{in}$., and 9 in. from the stagnation point. The 5-hole probe data was acquired in an attempt to visualize the freestream flow as validation of the VIST and to characterize the boundary layer. However, the boundary was too small to be resolved using only the 5-hole probe data. The flow visualization of the $12.19 \mathrm{~m} / \mathrm{s}(40 \mathrm{ft} / \mathrm{s})$ can be seen in Figure 13, which also shows that the boundary layer on the sidewalls were more than $50 \mathrm{~mm}(2 \mathrm{in})$ at each of the stations investigated.

The second test was a series of flow quality measurements using hot-wire traces taken along a vertical path 8 in. from the stagnation point. The hotwire tests were performed in order to further validate the flow acceleration in the VIST, to visualize the boundary layer, and to quantify the freestream turbulence in the tunnel. The hotwire traces were taken at $40 \mathrm{ft} / \mathrm{s}, 55 \mathrm{ft} / \mathrm{s}$, and $25 \mathrm{ft} / \mathrm{s}$ on all three test surfaces. Figure 14 presents the hotwire traces for all the surfaces and test cases and presents the design velocities at the 8-in. mark based on a linearly decreasing pressure coefficient variation assumed during the design of the roughness test surfaces. Figure 14 demonstrates that the design velocities match well with the experimental hot-wire velocities. While one of the objectives was to visualize the boundary layer for each case, Figure 14 demonstrates that even at $2.5-\mathrm{mm}(0.1$-in.) from the wall, the boundary layer for the smooth surface could not be detected. The boundary layer is noticeable for the $\mathrm{x} 10 \mathrm{x} 10$ surface; however, because of roughness interference with the hot-wire probe, the boundary layer is not detectable for the $\mathrm{x} 10 \mathrm{x} 25$ surface.

Figure 15 presents the turbulence intensities measured using the hotwire probe. Figure 15 demonstrates that the freestream turbulence values in the VIST are between 1\% and 1.5\%. As shown in Figure 14 as well, only the traces made using the $\times 10 \times 10$ surface demonstrate the presence of the boundary layer. In Figure 15, the x10x10 traces show a significant increase in turbulence intensity below the peaks of the tallest roughness elements which occur almost $100 \mathrm{~mm}$ (4 in.) upstream of the velocity profile trace. 


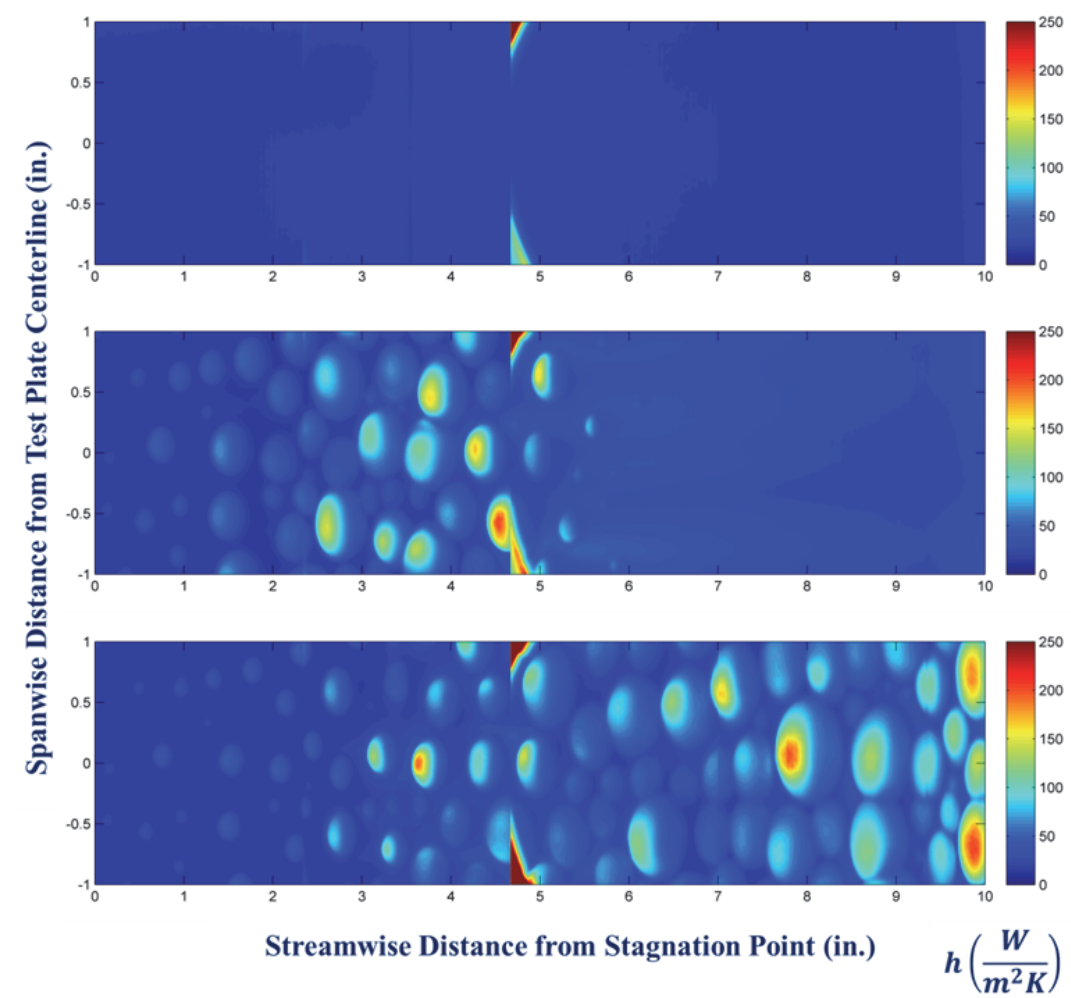

Figure 10. Measured Convection Coefficients with $7.62 \mathrm{~m} / \mathrm{s}(25 \mathrm{ft} / \mathrm{s})$ Throat Velocity (Top: Smooth surface, Middle: x10x10 surface, Bottom: x10x25 surface.)

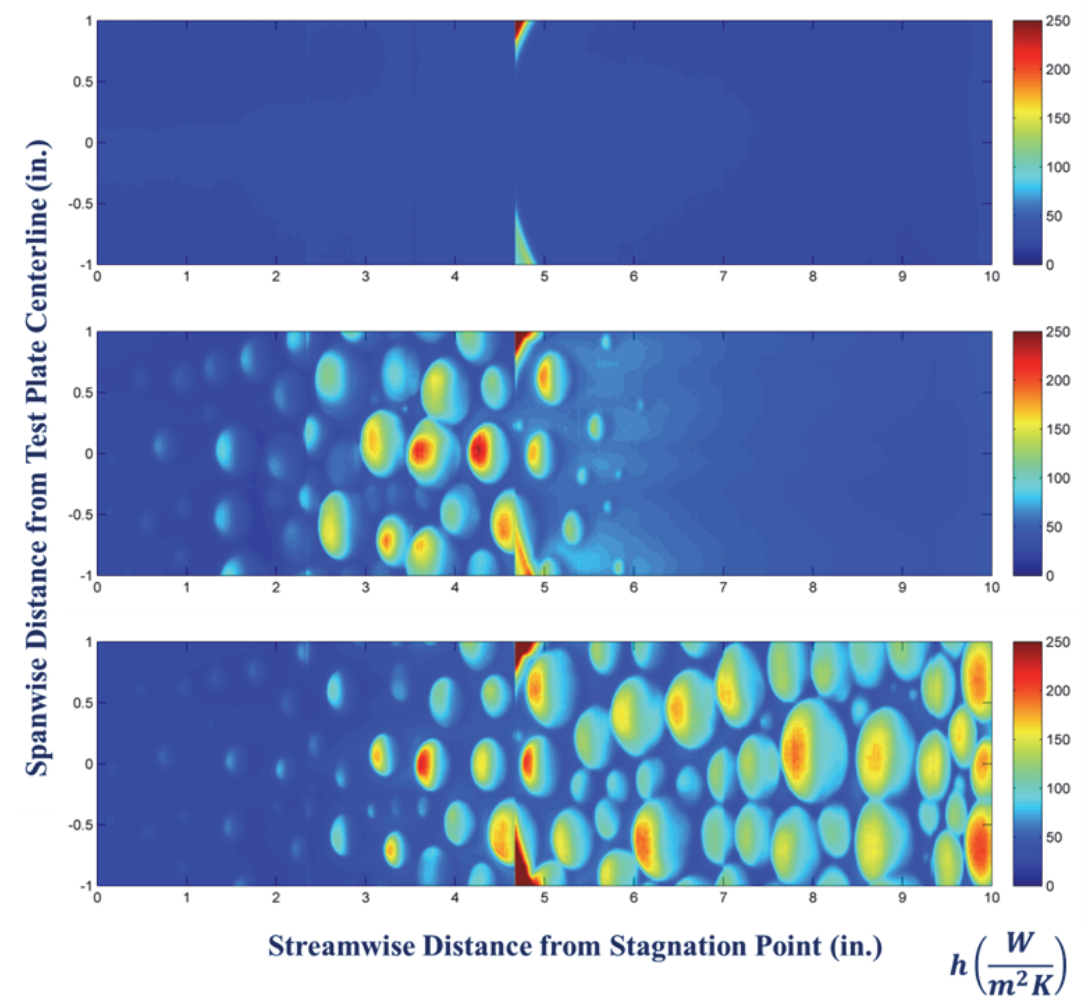

Figure 11. Measured Convection Coefficients with $12.19 \mathrm{~m} / \mathrm{s}$ (40 ft/s) Throat Velocity (Top: Smooth surface, Middle: x10x10 surface, Bottom: x10x25 surface.)

American Institute of Aeronautics and Astronautics 


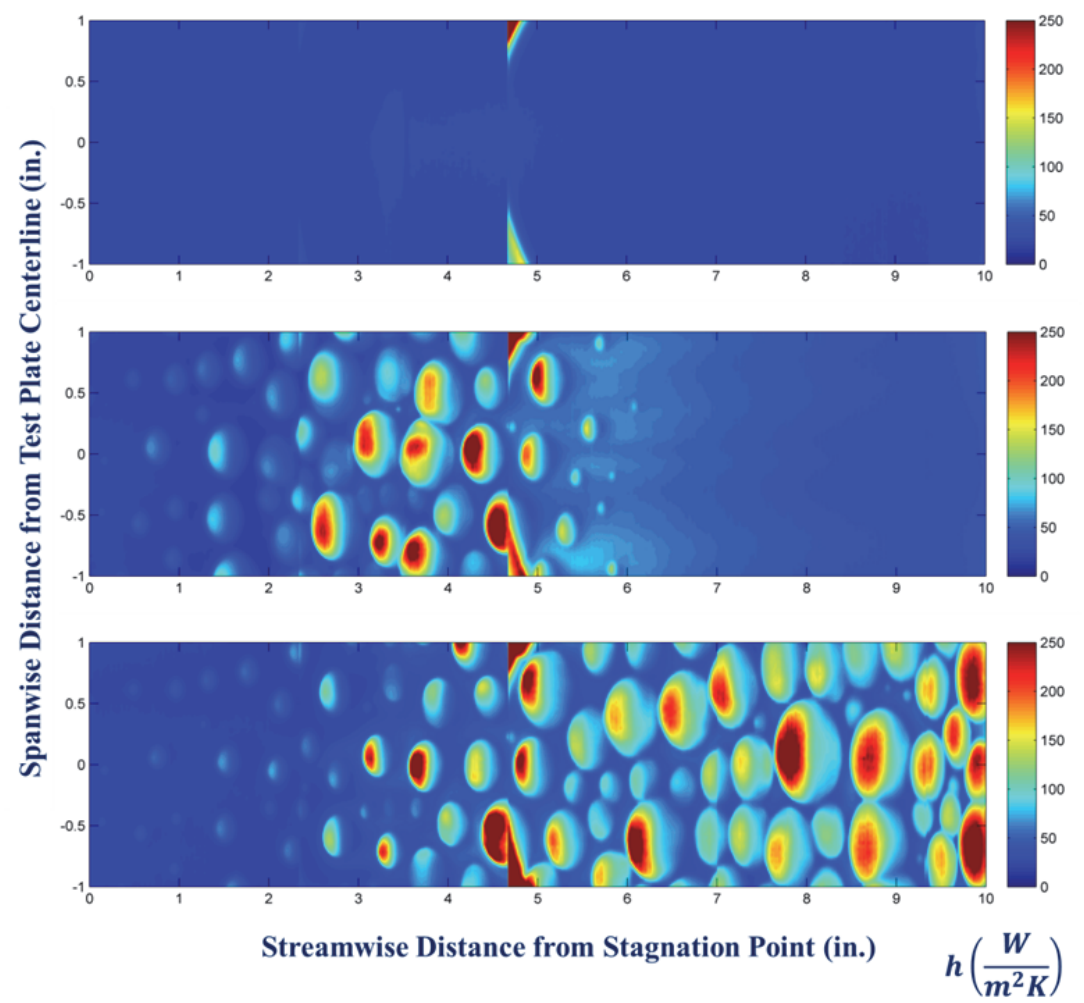

Figure 12. Measured Convection Coefficients with $16.76 \mathrm{~m} / \mathrm{s}$ (55 ft/s) Throat Velocity (Top: Smooth surface, Middle: x10x10 surface, Bottom: x10x25 surface.)

\section{Future Work}

The convection measurements presented in this manuscript were left in terms of the convection coefficients. The measurements were not placed in terms of dimensionless groups such as Frossling, Nusselt, or Stanton numbers. Placing the results in terms of dimensionless groups will be required to improve the generality of the measurements for validating computational tools. In future investigations, the proper spatial averaging approaches and better measurement of the local flow velocities will be used to determine the dimensionless convection parameters.

Beyond the scope of the current measurements, two design parameters will be varied in future investigations of stagnation region ice convection using the VIST. First, the shape of the roughness elements will be changed from hemispherical to cones. While real ice roughness is neither cones nor hemispheres, comparing the results for both types of roughness should provide enclosure limits for what would be expected of real ice roughness. Second, roughness plates for the VIST will be machined from aluminum instead of printed using a rapid-prototyping polymer. While not a perfect conducting material, the aluminum plates will act more like a real ice surface which is forced to be near-isothermal because of the freezing of the liquid water (Stefan condition). Each of the two new sets of surfaces will provide insight into the differences between the convective enhancement surfaces with modelled and real ice roughness. 


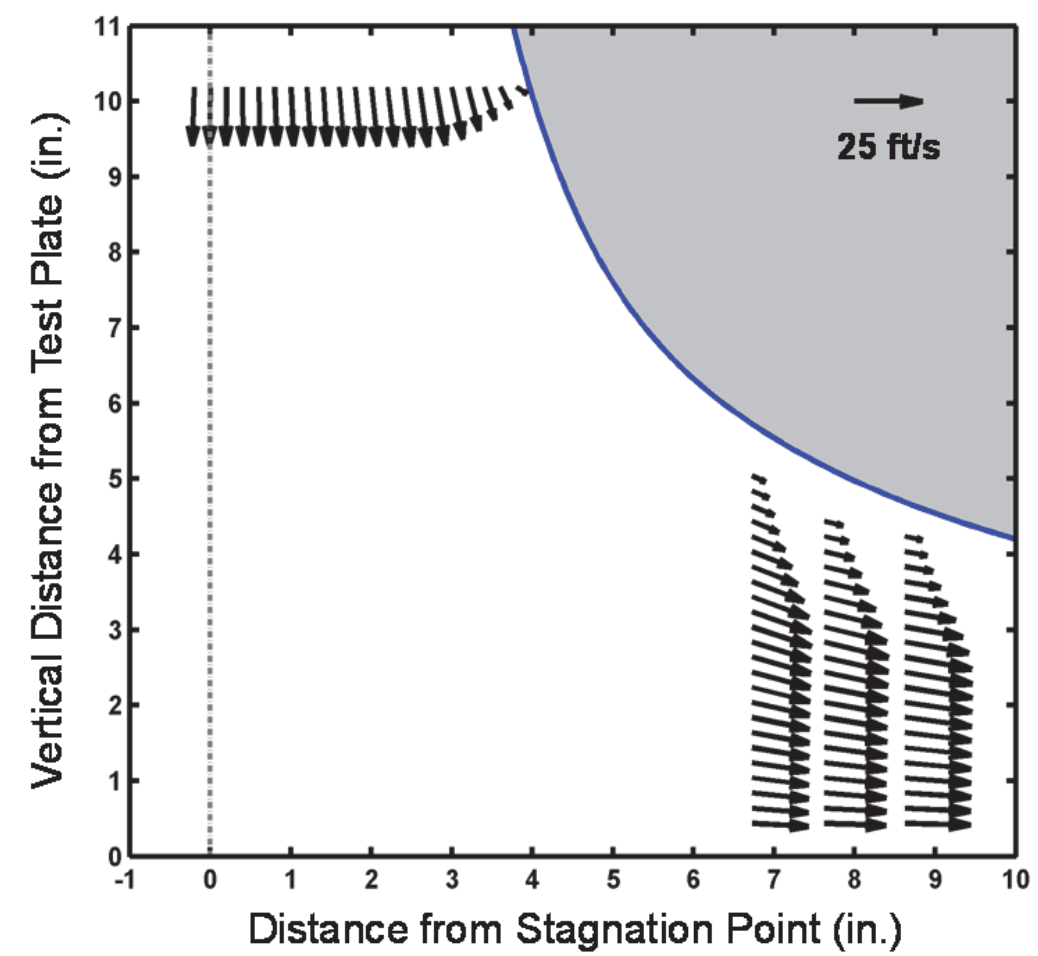

Figure 13. Visualization of Five-Hole Probe Traces for the $12.19 \mathrm{~m} / \mathrm{s}(40 \mathrm{ft} / \mathrm{s})$ Case for the $10 x 10 x$ surface.

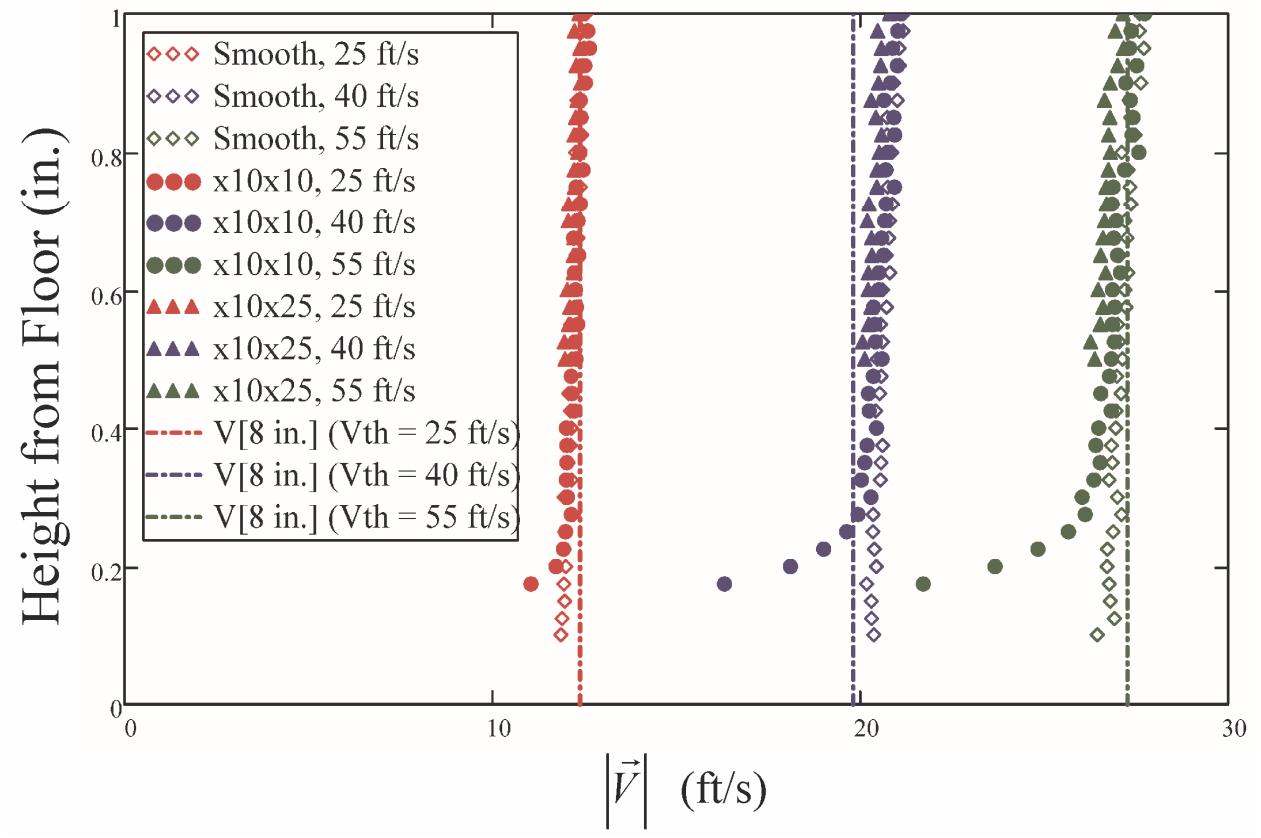

Figure 14. Hotwire Traces Acquired at $203 \mathrm{~mm}(8 \mathrm{in}$.$) from the VIST Stagnation Point$ 


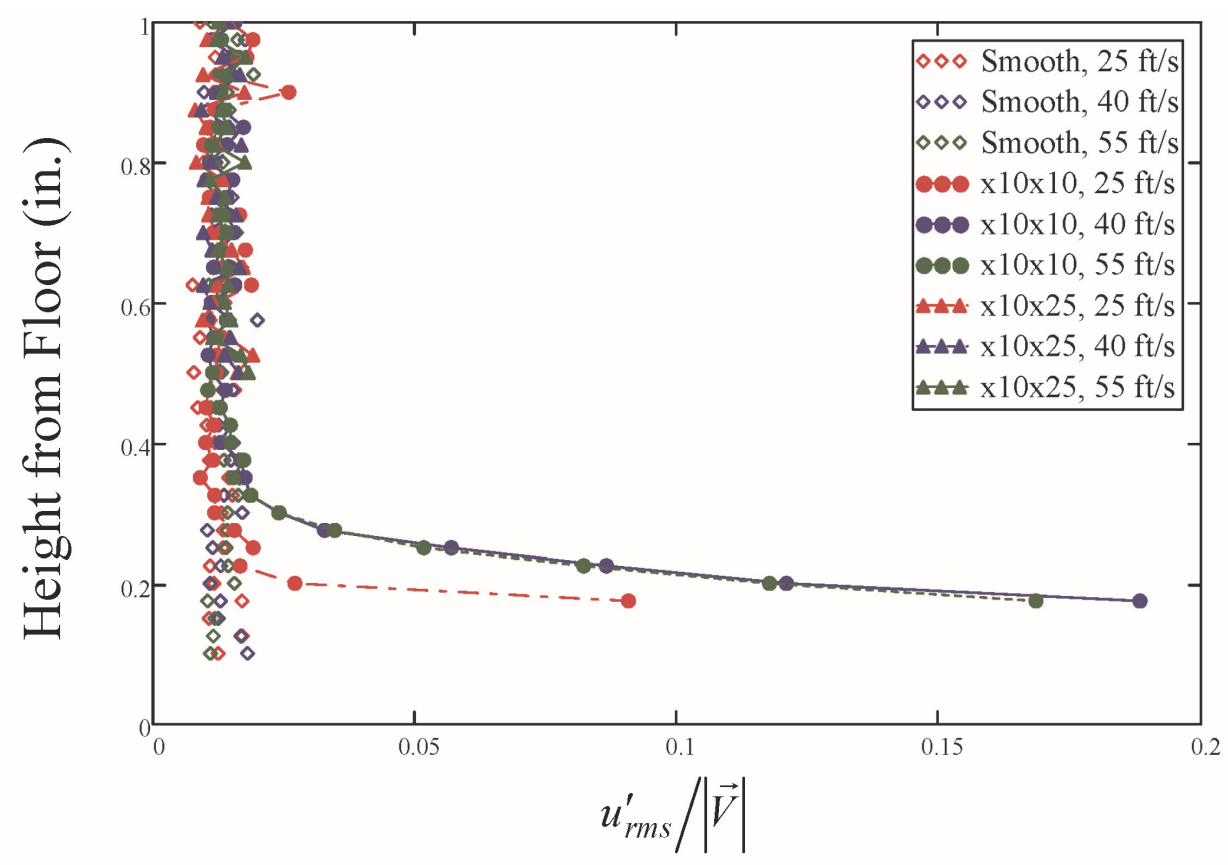

Figure 15. Turbulence Intensity Measurements from Traces Acquired at $203 \mathrm{~mm}(8 \mathrm{in}$.) from the VIST Stagnation Point

\section{Conclusion}

As part of a larger effort to understand the enhancement of ice roughness on convective heat transfer, this effort investigated the enhancement of ice roughness in the stagnation zone or $2 \%$-chord region of an iced NACA 0012 airfoil. The investigation was completed in the Vertical Icing Studies Tunnel (VIST) at NASA Glenn and attempted to replicate a moderate-time icing event where the smooth stagnation region was about to close because of the advancing roughness fronts. Because of the construction of the VIST, because of the limitations of the camera views of the plate, and because of the need for significant temperature differences between the surface and the freestream, the Reynolds numbers of the original NACA 0012 airfoil based on flow distance and based on roughness element size could not be matched simultaneously using the VIST tests. Flow measurements were also performed using a five-hole probe and a hotwire probe to investigate the flow quality inside the VIST.

The convection measurements demonstrated the substantial enhancement caused the roughness elements in the stagnation region. The convection measurements also demonstrated the expected behavior of increasing flux with increasing flow velocities. While limited by access to the test section through the infrared window access ports, the flow measurements demonstrated that the design assumption of a linearly decreasing pressure coefficient along the VIST test surface was reflected in the measured acceleration of the flow.

Finally, future efforts using the measurements presented here will focus on casting the measured convection coefficients in terms of the traditional dimensionless heat transfer parameters. Future experimental investigations of roughness enhanced convection in the VIST will focus on roughness element shapes other than hemispheres and will focus on capturing the effects of the Stefan condition by using roughness element materials with very high thermal conductivities.

\section{Acknowledgments}

The efforts in this paper were performed under the NASA Internships, Fellowships, and Scholarships Program at Glenn Research Center. The assistance of Mr. Robert Clark at NASA GRC and Mr. Ashley Orr at Baylor University was indispensable to the success of this research project. The authors greatly appreciate the assistance and help of Dr. Donald P. McErlean and Mr. Robert Blenden of L3 Integrated Systems in Waco, TX in manufacturing the heated test Plexiglas base-plate using their CNC routing system. Additional thanks are due to the fellow researchers and graduate assistants who have worked previously on this project: Mr. Logan Tecson, Mr. Charles P. Brown, Mr. Christopher Walker, and Mr. Timothy Shannon. Any opinions presented in this paper are those of the authors and do not reflect the views of NASA or the United States government. 


\section{References}

${ }^{1}$ Leary, W. M. (2002). We Freeze to Please: A History of NASA's Icing Research Tunnel and the Quest for Flight Safety (No. NAS 1.21: 4226,).

${ }^{2}$ Wright, W.B., "User Manual for the NASA Glenn Ice Accretion Code LEWICE," NASA/CR-2002-211793, 2002 .

${ }^{3}$ Olsen, W., and Walker, E., "Experimental Evidence for Modifying the Current Physical Model for Ice Accretion on Aircraft Surfaces," NASA TM-87184, 1986.

${ }^{4}$ Cebeci, T., and Kafyeke, F., "Aircraft Icing," Annual Review of Fluid Mechanics, Vol. 35, 2003, pp. 11-21.

${ }^{5}$ Dukhan, N., and Van Fossen, Jr., G. J., "Experimental Frossling Numbers for Ice-Roughened NACA 0012 Airfoils," Journal of Aircraft, Vol. 40, No. 6, 2003, pp. 1161-1167.

${ }^{6}$ Shin, J., "Characteristics of Surface Roughness Associated With Leading Edge Ice Accretion," NASA TM106459, 1994.

${ }^{7}$ Tecson, L. and McClain, S.T., (2013), "Convective Enhancement of Surfaces with Realistic Ice Roughness Distributions," 5th AIAA Atmospheric and Space Environments Conference, 24-27 June, San Diego, CA, AIAA2013-3060.

${ }^{8}$ Tecson, L. and McClain, S.T., (2013), "Modeling of Realistic Ice Roughness Element Distributions to Characterize Convective Heat Transfer," 5th AIAA Atmospheric and Space Environments Conference, 24-27 June, San Diego, CA, AIAA-2013-3059.

${ }^{9}$ Anderson, D. N., Hentschel, D. B., and Ruff, G. A., "Measurement and Correlation of Ice Accretion Roughness," NASA CR-2003-211823, 1998.

${ }^{10}$ Walker, C.W., McClain, S.T. and Shannon, T.A., (2014), "Convection from Ice Roughness with Varying Flux Boundary Conditions," 6th AIAA Atmospheric and Space Environments Conference, 16-20 June, Atlanta, GA, AIAA-2014-2463.

${ }^{11}$ Shannon, T.A. and McClain, S.T., (2015), "Convection from a Simulated NACA 0012 Airfoil with Realistic Ice Accretion Roughness Variations," SAE 2015 International Conference on Icing of Aircraft, Engines, and Structures, June 22-26, Prague, Czech Republic.

${ }^{12}$ White, E. B. and Oliver, M. J., (2005), "Experiments on Surface Roughness Effects in Ice Accretion," Presented at the AIAA 4th Theoretical Fluids Meeting, June 22-25, 2005, Toronto, ON, AIAA-2005-5190.

${ }^{13}$ McClain, S.T., Vargas, M., Kreeger, R.E., and Tsao, J.-C., (2015), "A Reevaluation of Appendix C Ice Roughness Using Laser Scanning," SAE 2015 International Conference on Icing of Aircraft, Engines, and Structures, June 22-26, Prague, Czech Republic.

${ }^{14}$ Lee, S., Broeren, A. P., Addy, H. E., Sills, R., and Pifer, E. M., (2012), "Development of 3D Ice Accretion Measurement Method," 4th AIAA Atmospheric and Space Environments Conference, June 25-28, New Orleans, LA, AIAA-2012-2938.

${ }^{15}$ McClain, S.T. and Kreeger, R.E., (2013), “Assessment of Ice Shape Roughness Using a Self-Organizing Map Approach," Presented at the 5th AIAA Atmospheric and Space Environments Conference, June 24-27, 2013, San Diego, CA, AIAA-2013-2546.

${ }^{16}$ Coleman, H. W. and Steele, W. G., (1999), Experimentation and Uncertainty Analysis for Engineers, Second Edition, John Wiley and Sons, Inc.

${ }^{17}$ Kline, S. J., and McClintock, F. A., (1953), "Describing Uncertainties in Single-Sample Experiments," Mechanical Engineering, Vol. 75, pg 3-8. 